\title{
Peer Review Procedures as Practice, Decision, and Governance - Preliminaries to Theories of Peer Review
}

\author{
Martin Reinhart \\ Humboldt-Universität zu Berlin, \\ Robert K. Merton Center for Science Studies \\ martin.reinhart@hu-berlin.de \\ Cornelia Schendzielorz \\ Humboldt-Universität zu Berlin, \\ Robert K. Merton Center for Science Studies \\ German Center for Higher Education Research and Science Studies \\ schendzc@hu-berlin.de
}

Abstract: Peer review is a ubiquitous feature of science and fulfills
three interrelated roles. Firstly, it is a mechanism used to assess
quality based on expert judgement (process). Secondly, it is a decision
mechanism used to distribute scarce resources, such as publication
space, funding, or employment (outcome). And thirdly, it is an
instrument for self-governance in science (context). This is poorly
reflected in public debates and, more importantly, in theoretical
conceptions informing research about peer review. To move beyond
such a "deficit model," we provide two preliminary considerations
that lay the foundation for a more encompassing theory of peer
review. First, the peer-review process can be divided into at least eight
different practices, which can in turn comprise a wide variety of
specific peer-review procedures when combined. Second, peer review
not only provides evaluative decisions, but, more importantly, also
provides the legitimacy for these decisions. Thus, an encompassing
view of peer review should integrate process, outcome, and context. 
We argue that such a view could start by theorizing peer review as a form of government, not unlike democratic government, which has grown historically around concerns for legibility, responsibility, and responsiveness (Rosanvallon) in a similar way to the Mertonian norms.

\section{N T R O D U C T I O N}

Peer review is a ubiquitous feature of science dating back to the $17^{\text {th }}$ century. As the basic and most adequate form of quality control, peer review seems irreplaceable to most scientists. Despite its central importance and long history, peer review is mainly discussed with respect to its deficiencies. Public debates have little to say, however, about the merits of peer review and the mechanisms that make it work. A frequent trope in this context refers to peer review as the worst form of quality control, except for all the others. As a consequence, attempts to reform or improve peer review primarily aim at eliminating or alleviating such deficiencies. A "deficit model” offers only a limited understanding of how peer review works, and measures to address deficiencies may have significant and negative unintended consequences as a result. In light of the many current issues that call for changes in how quality is controlled in science (RRI, translation, reproducibility, misconduct), a more comprehensive understanding of how peer review works is urgently needed.

A similar observation can be made with respect to the research literature. Peer review research started as a reaction to public criticism, most notably with political concerns over cronyism and the work by Cole \& Cole in the 1970s (Cole et al. 1977; Cole \& Cole 1981; Baldwin 2018). By and large, it has retained a focus on perceived deficits and ways to improve on them up to the present. As such, it is perfectly attuned to the need in public debates for evaluative judgements and quick guides for action. However, the field has, at the same time, become bigger and more diverse, so that the time may have come to challenge the premises of the deficit model and ask for a more encompassing understanding of peer-review processes. Despite the large number of empirical studies, a discussion of how peer review works as a procedure for quality control and what useful theoretical renderings of this process might look like is still missing. Such a discussion is sorely needed to move the field from primarily evaluative to more scientific perspectives (Hirschauer 2004).

Instead of providing a theory of peer review that overcomes the deficit model, our goal in this paper is a preliminary one. Existing (empirical) research is full of explicit and implicit conceptualizations of peer review, which offer a common denominator on which theories of peer review can be built. We argue, first, that a common understanding includes peer review as a procedure to assess quality, peer review as a mechanism to decide on 
scarce resources, and peer review as an instrument for (self-)governance in science. Since the deficit model has primarily focused on peer review as a decision mechanism, we expand, second, on what it means to conceptualize peer review as a procedure for quality assessment and as an instrument for governance. Based on a simple typology, we conclude by integrating these three understandings and suggesting the main theoretical concerns that future theories of peer review may consider. These concerns result from the claim that the success of peer review is predicated on it combining issues of scientific quality with issues of political legitimacy that remain inseparable for any empirical analysis.

\section{The “Deficit Model” of Peer Review}

If peer review is considered any procedure in science that is used to allocate scarce resources by invoking expert judgement on the epistemic qualities of an object, then peer review is a highly diverse phenomenon with a long history. Its diversity stems from all four aspects of this definition. Objects can be papers, books, research projects, people's careers, funding programs, or organizations. Epistemic qualities can be disciplinary, interdisciplinary, or even transdisciplinary. Expert judgment can be individual, collective, or even algorithmic. And scarce resources can be publication space, funding, careers, attention, and prestige. ${ }^{1}$ As such, peer review encompasses many, if not most, of the institutionalized procedures of evaluation in science: journals, books, conferences, funding, professorships, and a myriad of institutional and program evaluations (Jasanoff 1990). Its historic origins can be traced back to the scientific associations, such as the Royal Society, from the $17^{\text {th }}$ century (Barnes 1934; Biagioli 2002; Kronick 1990; Lock 1985; Spier 2002; Webster 1967; Zuckerman \& Merton 1971). ${ }^{2}$ These initial forms of evaluative witnessing (Shapin 1994) and selecting were mostly informal and local. Even though they spread alongside the growth of the science system, peer review only evolved into a ubiquitous feature of science in the second half of the $20^{\text {th }}$ century (Guston 2000; Jasanoff 1985; Baldwin 2018).

The rise of peer review must be regarded in the context of increased and more specific public funding for research after the Second World War (Jasanoff 1990; Guston 2000). Baldwin's (2018) account is highly instructive here as she pinpoints the moment in US-American politics in the 1960s and 1970s when referring to peer review became taken for granted: on the one hand, when public spending on research had to be justified and, on the other, when the quality of research had to be ensured. From that point on,

\footnotetext{
${ }^{1}$ None of these lists are meant to be exhaustive.

${ }^{2}$ For a dissenting view on determining the historical origins of peer review according to the convention of the scientific revolution in the $17^{\text {th }}$ century, see Rip (1985) or Laine \& Mulrow (2003).
} 
peer review became the procedure that regulated the boundary between science and politics, and more generally between science and society (Guston 2000; Guston 2001; Weingart 2001). It became successful in this role, not because there was convincing evidence that peer review would be the best procedure, either epistemically or politically, to regulate science. Rather, it became a matter of course because it represented the consensus between political and scientific actors after science became a politically contested issue, first after allegations of financial mismanagement and then of cronyism. As such, peer review itself only became a contested issue when allegations could be made that it has serious deficiencies. Since then, public debates about peer review have little to say about its merits and much about its flaws.

The list of alleged flaws and deficits is long and has changed little over the last 40 years: conservatism, corruption, bias, lack of transparency, inefficiency, ineffectiveness, low reliability, low validity, overburdened reviewers, and much more (Reinhart 2012: p. 50ff). It seems that these recurring allegations have less to do with how peer review actually works and more with how important peer review has become. Whatever the overarching contested issue is at the time-interdisciplinarity, translation, responsible research and innovation, reproducibility, misconduct, etc.-peer review is always part of the debate. Due to its centrality, it must at least be either part of the cause or part of the solution. Whatever the problem, it is due to the deficits of peer review, and the way forward lies in peer review reform or in alternatives to peer review. At least, this is how these public debates always seem to play out. We call this the "deficit model": Peer review is only of interest when problems arise, then calls for urgent changes follow. The way peer review actually works, however, is taken for granted and requires no immediate action. Along the lines of a famous quote by Winston Churchill, the perennially recurring slogan for the deficit model can be summed up as follows: Peer review is the worst form of quality control, except for all the others.

It seems then that these public debates are only secondarily about peer review. One might expect the script for such debates to change over time according to the current state of research on peer review. The question of whether one of the proclaimed deficits is actually prevalent could be resolved through research, for example, whether there is gender bias or not, and the debate should change accordingly. It seems that this is not happening, even though the number of empirical studies on peer review has been growing considerably. (Gender bias is still a contested issue both publicly and in the research literature.) We think that this state of affairs has at least three causes. First, most empirical studies employ a case-study approach (e.g., of one journal or one funder), and comparative work is very rare. Second, most studies have relatively small sample sizes, and the robustness of results suffers accordingly. Third, most studies follow the deficit model in that they primarily test for one (or several) of the alleged deficits of peer review and thus fail to give a comprehensive view of peer- 
review procedures. The first two causes would be easy to overcome if there were more access to data from journals, funding organizations, and governments. Despite national transparency and accountability laws and more researchers attempting to gain access to data, the field has seen only minor progress on this front, and it still seems that limited access to data will be a central issue for the foreseeable future. The third cause, however, is more difficult to overcome and little progress has been made here.

Considering the abundance of public debate and research, it is surprising that there is very little theorization of peer review. Peer review is frequently introduced as playing "a key role” in science without much qualification as to what this key role implies. Most authors treat the role of peer review and thus its theoretical relevance either as self-evident or as pertaining to a deficit. Whether a deficit relates in an important way to what the role of peer review is in theory is rarely discussed. As a consequence, there seems to be a need for specific rather than general claims as to what the role of peer review is and how such claims help in determining what research questions can be deemed relevant. Overcoming the deficit model will therefore require making explicit (and testable) claims about the role of peer review that relate to the general sentiment that peer review is "one of the fundamental conditions of possibility of academic knowledge and the construction of its value" (Biagioli 2002: p. 11). In addition, such theoretical claims may also help explain why the deficit model has become the most prevalent folk theory of peer review.

What Is A Potential Basis For Theories OF PEeR REVIEW?

Similarly, the research literature is mainly focused on finding out whether everyday criticism of peer review has some validity. Equally notable is the absence of a discussion on possible theories of peer review. Public debates and research literature seem perfectly attuned: One proclaims a serious deficit at the heart of science (conservatism, bias, inefficiency, etc.), while the other sets out to prove or disprove the critics empirically. And since science never provides definite answers: rinse and repeat.

Why and how peer review actually works as a procedure for quality control and (self-)governance has been a peripheral topic at best (Neidhardt 2016). To move beyond the predominant focus on the decisions and outcomes of peer review and beyond the deficit model with its evaluative orientation (Hirschauer 2005), we fall back on very basic assumptions about the role of peer review. In a very general sense, peer review does not just consist of outcomes, but rather these outcomes are produced by a process within a certain context. Andrew Abbott's processual sociology (2016) provides a perspective that binds these three elements (process, outcome, context) together in a highly abstract theoretical fashion. We concretize the two underdeveloped elements for the case of peer review by drawing on the 
work of Stefan Hirschauer (for process) and Friedhelm Neidhardt (for context). An ethnographic perspective reveals that a series of interrelated practices make up a peer-review procedure, such as various forms of reading, editorial discussions, or joint revising of texts (Hirschauer 2010; Lamont 2009; Mallard et al. 2009; Pontille \& Torny 2015). A contextualizing perspective indicates functions peer review fulfills beyond decisional outcomes; it legitimizes these decisions to a diverse set of audiences (first among them scientists themselves and actors in science policy) and, as a result, also legitimizes itself as an institution to (self)govern science (Neidhardt 2016; Guston 2000; Jasanoff 1985). To relate these processual aspects of peer review to their legitimate context, Niklas Luhmann's concept of "legitimation by procedure" (1983) is helpful as it allows decisions to be analyzed not as self-evident because they represent the truth, but instead as acceptable because they are recognized by a community of stakeholders.

In a more vernacular language, these three elements (process, outcome, context) can be summarized as three interrelated claims about the role of peer review, which can also be found either implicitly or explicitly in much of the empirical literature: Peer review is a mechanism used to assess quality based on expert judgement; peer review is a decision mechanism used to decide on scarce resources, such as publication space, funding, or employment; peer review is an instrument for self-governance in science (Reinhart 2012: p. 189ff).

\section{Practices (i.e. Process): Activities in Peer REVIEW}

In order to understand peer review as a process, it is necessary to first consider the actual practices that make up a peer-review procedure. Even though peer review comes in many forms and even though ethnographic descriptions of a variety of processes are rare, a limited number of frequently occurring practices can be discerned. We propose differentiating between at least eight such practices that occur as purposeful activities. As individual elements, they can be found in many peer-review procedures, and by combining them, they can be used to describe most procedures, ranging from very simple to very complex ones. ${ }^{3}$

Postulating activities: We understand the submission of a manuscript, a grant proposal, or a job application as a request for approval of the related claims. The claim of publishability, the claim of eligibility for funding for a project or person, and the claim of matching the advertised job profile and

${ }^{3}$ These activities have been identified through empirical analyses of peer reviewing procedures in public research funding. They have been elaborated based on in-depth mixed-method analyses of different funding schemes, namely of the DFG in Germany and the SNF in Switzerland, including single project funding, funding for collaborative research consortia, and career funding. For more detailed explanations, see (Schendzielorz/Reinhart 2020; Reinhart/Schendzielorz 2020). 
being able to fulfill it competently are all requests for acceptance. These postulations create the cause for assessment, its execution, and its organization in procedures in order to enable an evaluation-based decision later on.

Consultative activities: We regard the processes in which the manuscript, the proposal, or the application (and if so the personal oral presentation) is reviewed as a counselling practice. The written reviews, notes, and verbally expressed evaluations of the postulates are obtained as advisory expert opinions in order to assure a competent evaluation.

Decision-making activities: We consider decision-making activities to be the process in which the entitled participants in the respective procedure decide-be it on the basis of grades, rankings, reports, or oral presentations - whether to accept or reject the postulate.

Administrative activities: By administrative activities, we refer to the processes in which postulates are received and their treatment is launched and coordinated. These activities are usually provided by organizations that make use of peer review and are carried out by their representatives such as editors, editorial managers, or permanent staff of funding agencies. To define administrative activities as a distinct practice takes account of the fact that peer-review procedures are executed under the premise of an existing organizational framework (journal, funding agency, universities and their public and or private investors).

Debating activities: We define debating activities as the processes in which the reviews, notes, and evaluations that contribute to the assessments are exchanged, commented, and discussed. The debating practices take place, for instance, in editorial boards, reviewing panels, or appointment commissions and can contain written reviews in running text, memos, speaking notes, numerical votes, or oral contributions.

Presenting activities: We refer to processes as presenting activities in which the postulating authors or applicants for grants or jobs introduce themselves and present and explain their proposal, profile, and request in person, which includes answering any relevant questions. In these activities, the postulators are involved directly in the evaluation process. These activities occur in multi-level procedures for job applications and for personalized grants as well as for project and collaborative project funding, for instance, in the case of on-site visits and inspections. Most commonly, they follow a more or less in-depth evaluation of written postulates.

Observing activities: We classify these activities as the processes in which the assessment is monitored in order to control procedural compliance with regard to the respective tasks, rights, and duties of each role, its course, and the overall objective. These activities often require the results to be documented or reported to the decision-making authorities.

Moderating activities: The regulated procedure as such requires moderating activities that accompany and, if needed, explicate and (re)explain the processes. The more complex and multileveled they are, the more the interplay between different activities needs to be explicitly 
concerted and aligned throughout the ongoing procedure, for example, by introducing and guiding participants in the procedure. This can also mean chairing the meeting during discussions and when presenting applicants.

DERIVING PROCEDURES FROM PRACTICES: TyPES OF PEER REVIEW

The different activities each correspond to specific tasks and responsibilities, some executed by different, some handled by the same persons but in separate phases of the procedure. To be specific, the postulating authors or applicants themselves are never involved in consultative or decision-making activities in relation to their own proposals, but are potentially involved in the evaluation of other postulates. Depending on the procedure, consultative and decision-making activities can be carried out one after the other by the same person, or they can be strictly separated. In the latter case, it is often the report created during the observing activities that provides the basis for the decision on the results of the consultation and discussion.

The great variance in the peer-review procedures in terms of effort and complexity is also due to the fact that all of the activities mentioned above can be carried out by multiple people, but hardly any of them necessarily require more than one person. Postulates can be submitted and presented collectively or individually according to preference, disciplinary convention, or funding. The administrative, moderating, and observing activities are presumably assigned according to the number of postulates, the narrow or broad thematic scope, the length and complexity of the procedure, and the available resources. In the course of consultation, multiple reports are usually required in order to obtain a variety of perspectives, but this requirement is not always met. Therefore, only the debating activities, in which different opinions are debated and weighed against each other, are necessarily collective. In the case of journal editors, who sometimes still decide alone on the acceptance and rejection of manuscripts, their activities remain collective to the extent that their decisions are allegedly founded on expert opinions, which, in their view, represent the other participants of the discussion.

Building on this, we can now discern different types of peer-review procedures, which can be located between the extremes of a minimum and a maximum procedure.

At first glance, the minimum peer-review procedure requires a postulating activity, a consultative activity, and a decision-making activity in which the postulate is accepted or rejected. However, this three-part model would also be applicable to any counterreading of manuscripts by colleagues, who then make comments, whereupon the author must decide whether and how to integrate them. We could argue for this model in view of which actions are being carried out for what purpose, but it would not 
sufficiently define the subject under discussion in our contribution to the theorization of peer review as a procedure that enables decision-making and self-governance in science.

Thus, at second glance, the question arises as to whether the common understanding of peer review must include an administrative activity, in which postulates are received and their processing is initiated and coordinated. As mentioned above, as an instrument for self-regulation in science, peer review is always embedded in an organizational framework (e.g., journal, funding agency, university, institute, or academy), in which administrative activities take place (see Neidhardt 2016: p. 271; Reinhart 2012: pp. 150-155). The minimum procedure of peer review hence consists of four elements: postulating, administrative, consultative, and decisionmaking activities.

The spectrum's other pole is marked by a maximum procedure, which can be found, for example, in the application for long-term funding or largescale research collaborations. Here, more elaborate peer-review procedures are used, which, in addition to the four basic elements, differ as follows: debating activities, presenting activities, observing activities, and moderating activities that accompany the process. The maximum peer-review procedure is thus composed of all eight elements.

\begin{tabular}{|l|l|}
\hline Minimum & Additionally up to the Maximum \\
\hline Postulation & Discussion \\
\hline Administration & Presentation \\
\hline Consultation & Moderation \\
\hline Decision & Observation \\
\hline
\end{tabular}

\section{PEER REVIEW IN CONTEXT}

The variety of peer review procedures can be seen as the result of the many possible combinations and variations of these eight elements. This, however, raises the question as to why so many combinations, and thus variants, of peer review are needed. A naive understanding of scientific selfgovernance would assert that peer review is all about expert judgement and, thus, the only relevant aspect is finding the best peers who will "know quality when they see it”. From such a view the many variations of peer review procedures seem unnecessary. Moving beyond the deficit model and recognizing the procedural differences, however, prompts us to ask about the context in which peer review is used and which functions it fulfills, either with individual elements or combination of elements. Stefan Hornbostel (2016) suggests that evaluation procedures in science can fulfill six different functions: the knowledge function, in which the evaluation provides 
information on the nature, effect and efficiency for the participants; the control function, which ensures compliance with target values and auditing procedures; the dialogue function, which serves to stimulate selfunderstanding and communication processes; the legitimation function for decisions and accountability; the evidence function, in which meta-analyses are carried out in order to make evidence-based decisions; and the public function, which is constitutive for ratings and rankings (Hornbostel 2016: p. 245).

In general, we would assume that all peer-review procedures serve multiple or even most of these functions in one way or another. Furthermore, individual elements of procedures may serve more than one function over different procedures or even within the same procedure. We see these six functions as a heuristic to move away from common sense understandings of peer review and to emphasize the move beyond the deficit model where quality and legitimacy are the result of process, outcome, and context. As such, we suggest some frequent combinations of elements and functions to move towards the more general question as to how they produce quality and legitimacy.

The knowledge function is often served by a combination of postulate, consultative reviewing, and discussions in presenting and debating activities. This can go hand in hand with the dialogue functionwhen the postulate is proceededby presenting activities of the postulators and a question-answer session, continued and deepened in debating activities (e.g., in panel or board sessions), and resulting in feedback to those who submitted a postulate. Knowledge about the scientific quality of postulates must be explicated in peer review procedures, providing the basis for a dialogue about quality. The close relation between knowledge and dialogue has prompted Hirschauer to address peer review primarily as a communicative process.

With respect to legitimacy, the control and legitimation functions are decisive. Control is exercised by means of publicly accessible information on opportunities for publication, funding, and jobs, including the respective rules such as who is eligible to postulate or what the relevant quality criteria will. As this is public information it serves as the basis for accountability towards the relevant scientific communities as well as towards further stakeholders e.g. in politics. In addition, elements of administration, moderation, and observation provide control and legitimation as internal and organized parts of peer review procedures. Control, legitimation, and public functions of peer review connect internal and external aspects of how procedures produce legitimacy. This close relation has prompted Reinhart to address peer review primarily as an organized or organizational process.

The various types of peer-review procedures ranging from more minimalist to rather maximalist procedural forms thus reflect different functional demands from different stakeholders, such as the readers, the scientific community, the citizens as taxpayers, academic colleagues, university staff, scholars, and students. Hence, the complexity of the peer- 
review procedures and their elaborate design are also determined by the variegated pressures for legitimacy. This can be further predicated on the sustainability of staffing or funding, the amount of financial resources allocated, or the reputation of the journal or position.

\section{How Do PEER-REVIEW Procedures Produce QUALITY AND LEGITIMACY?}

The manifold practices and functions that make up the diverse sets of peer-review procedures demonstrate that determining the quality of the scientific work is only part of the role played by peer review. Equally important is that these procedures provide legitimacy for judgements of quality. That is, in essence, what procedures do in general (Luhmann 1983). Separating the quality and the legitimacy aspects is impossible in practice because of the processual nature of peer review. However, our typology of practices makes it possible to address how different peer-review procedures combine these elements and thus produce combinations of quality and legitimacy that are context specific.

With regard to ensuring quality, those procedures that, as is done in many journal peer-review processes, ascribe great importance to consultative reviewing derive their quality assurance and legitimacy to a large extent from the competent written expert opinions and their subsequent discussion. Those procedures that provide considerable time and space for presenting and debating activities, in panel assessments, on-site evaluations, etc., complement the legitimacy based on written expert judgement and also draw legitimation from discursive and deliberative elements, to a considerable extent. If observing activities are also highly developed, standards such as compliance with procedural requirements to ensure equal treatment and avoid bias are also invoked as legitimation-relevant features. In this respect, it is also instructive to see who guarantees that a procedure unfolds as fairly and impartially as possible. This task is often performed by representatives of the organizations. If observing activities overlap heavily with administrative activities, legitimacy through procedure is presumably very pronounced and generally weighty. If observing activities overlap strongly with consultative and debating or even decision-making activities, it is questionable whether the separation of roles can be maintained without assigning them to separate people. Otherwise, the allegation might be raised that these activities are not effective and, thus, are "just for show."

Concerning legitimation through procedure, we can assert that the more complex and multi-levelled the procedure and the targeted selective transparency between the individual stages of the procedure are and the more pronounced the separation of functions and personnel and the division of labor are, the more legitimacy is based on the procedure itself. As a result, different procedural types of peer review imply different techniques to provide quality assurance and legitimacy because the way in which the 
different activities are combined affects the way legitimacy is generated through procedure. This is not to say, however, that procedures produce legitimacy irrespective of who participates in them. The power of peer review procedures to decide on scarce, and thus contested, resources seems to be predicated on scientists playing roles that are seen as key to the procedure. If only other scientists are involved, the scientific community is the central stakeholder, whereas the inclusion of representatives of the funding organizations or other stakeholders are signs that e.g. science policy or the public are also addressed and affected to some degree.

\section{M P L I C A T I O N S}

Our claim at the beginning of this paper was that the deficit model is tied to a theory of peer review that mainly focusses on the results, that is to say the decisions, of procedures. Research questions thus center around issues such as reliability, validity, and fairness. What is neglected by such accounts are two commonsensical aspects of peer review that make decisions both possible and relevant: process and context. By exploring these two aspects, we have shown, first, that the processes through which decisions are reached are highly diverse and practically complex. As such, they incorporate a multitude of practices and criteria that are difficult to capture solely from outcomes. We have illustrated, second, that the contexts of peer-review procedures extend beyond scientific communities of shared quality standards and that these contexts co-determine the outcomes. By giving equal weight to the process, decision, and context aspects, we conclude that the role of peer review lies in inextricably linking the quality and legitimacy of judgements about scientific work. In other words, peer review is as much about science as it is about politics. Theorizing peer review should therefore start from the notion that the primary role of peer review is to link self-governance and external governance of scientific work.

Starting from this notion, theoretical claims about peer review can be taken in different directions. Some possibilities were mentioned above; e.g. peer review as (boundary) organization or peer review as a communication process. Merton famously linked "science and the social order" through the democratically inspired scientific ethos, which had organized scepticism, i.e. peer review, as one of the four norms (Merton 1938, 1968). Following up on that Mertonian intuition our account here could be used to balance the normative with the processual aspects of peer review. Drawing additional inspiration from Foucauldian perspectives, we can ask: Who governs through peer review and who is governed by it? With reference to the distinct activities and our typology of minimum and maximum procedures, we can discern three spheres in which governance in and of science through peer review calls for legitimation: scientific community, science politics, and society, which respectively encompass scientists, including researchers in humanities and social sciences, politicians, and citizens in general as the 
populations being governed. Hence, these spheres overlap, for example, in "boundary organizations" (Guston 2000) such as national research agencies or coincide with societal concerns.

In the scientific community, self-governance through peer review is legitimized by safeguarding the professional competence of the assessments, guaranteeing an intersubjective coordination of the judgments between several experts and editors, and providing a functional separation of roles and division of labor (Reinhart 2012: pp. 125, 176, 183). This sphere deals with the creation of legitimation by procedure with regard to quality assessment in the scientific community. Its main concern is the sphere of science policy, representing an already external governing authority given that it assures the legitimacy of the decision. In essence, it consists of making an adequate selection of articles worthy of publication, research projects eligible for funding, or job applicants competent to occupy the position because in this way, the scientific system shows it is capable of making gradual decisions according to relevance, importance, and significance for the disciplinary scientific discourse and labor.

The distinction between legitimation addressing the scientific community and legitimation addressing concerns of science policy lies at a procedural level. In both directions, the objective is "to do justice to the matter," that is to say, to carry out an evaluation appropriate to the object in question, and this requires the criteria that have been put in place to be explained. For only then can the decision be justified and made plausible by means of outlined criteria-which can include science policy arguments and reasons - both to the scientific community and to actors in science policy.

The governance of the societal sphere involves the justification of peer review as an adequate mechanism of self-regulation in science, in some way supervised externally and governed by science policy actors. This means that peer review also justifies itself and the form of governance it provides to other societal spheres, especially since the logic of other spheres is already making its way into peer-review procedures in the form of publishers pursuing economic interests and public funds or foundations with latent political interests. Thus, the legitimacy of procedures rests on orders of justification (Boltanski/Thévenot 2006) and is always a political issue.

The three spheres of governance for and in which legitimation is generated are linked and refer to each other. For example, trust in peer review as a functioning decision-making mechanism itself can only be maintained if procedural legitimation can be used as a justification in cases of doubt, retraction, or possible misconduct. Inversely, comparing different interpretations and assessments of various dimensions of the evaluation requires weighting and a reduction in complexity, which can only be achieved taking into account the concrete decision. Trust in peer review as a functioning mechanism for externally supervised self-regulation in science is therefore based on this reliable decision-making ability. By the same token, the quality of peer review also refers to the extent to which these 
communication channels between the three spheres of legitimation exist and can be made transparent and plausible if necessary.

Furthermore, the way in which the spheres of governance are linked with each other reveals the sources from which the legitimacy of peer review is derived. The triad of legitimation in peer review firstly refers to legitimacy immanent in science, which is ensured by means of the expert quality assessment of scientific contributions (manuscript or grant proposal) by competent peers. Secondly, it refers to the jurisprudence in which legitimacy is guaranteed by the neutrality of the judgement. "Although peer review is not a legal concept, it is invoked by scientists and academics as the axiom that informs most of their practices. It functions as an article in the tacit 'Constitution' of the social system of science (not unlike the way democracy functions in the discourses of modern liberal economies)” (Biagioli 2002: p. 13, see also footnote). Thirdly, selection and qualification as a competent peer draws on the political legitimacy of power, which is derived from the forms of representation of the population concerned, legitimized in procedural terms (by election, status, function, education, etc.). This once more reveals the relation to other spheres of society, especially to politics, in whose orders of logic and justification (e.g., academic reputation) the legitimation in peer review is embedded.

The fact that peer review is as much about science as it is about politics has consequences, which reveal themselves in the way this form of governance is legitimized. It is now evident that the question of legitimizing a form of governance points beyond the realm of science and refers back to political and civic notions of legitimacy. From this perspective, the principles of democratic legitimacy identified by Pierre Rosanvallon (2018) are instructive. Accordingly, democratic legitimacy is based on impartiality, reflexivity, and even proximity to coexistent particularities (Rosanvallon 2018: p. 30). We can now pinpoint these criteria with regard to the shared concerns of scientific community, science policy, and civic society as follows: Impartiality comprises a distancing of particular interests with respect to party positions or divergent schools of thought; reflexivity implies the consideration of different forms of knowledge and potential innovation according to multiple forms of expression of the common good; proximity entails the recognition of different epistemological paradigms with respect to the equivalence of all particular interest groups or research approaches. More than a simple majority principle is needed in order to achieve stable legitimacy that can cope with democratic claims, no matter the sphere of governance or governed collective from which they originate.

\section{CONCLUSION}

This process-oriented approach identifies the nexus of quality and legitimacy as the central theoretical concern in the research on peer review. It has the advantage of being applicable to both journal peer review and to peer reviewing of grant proposals, third-party funding, and staffing 
procedures, such as appointment procedures for professorships. Within the broad spectrum between minimum and maximum procedures, the different types and variants of peer-review processes can be understood as different modes of governance with regard to their function as an instrument for the (self)regulation of science.

We speak of modes of governance because it is a matter of exercising power and agreeing on maxims to build and establish legitimate forms of control. This refers to the form of power that Foucault called "governmentality," which aims to govern the population (2006). This is based on Foucault's relational concept of power, according to which power is a form of acting on the possible actions of others. In contrast to violence or coercion, this approach to power implies freedom and "marge de manoeuvre" of the respective others. Accordingly, governing is an action pervaded by power, striving to structure the scope for action of others (Foucault 2005: pp. 285-286). In the case of peer review, power is exercised in the form of the decision on how scarce resources can be distributed as fairly and effectively as possible regarding scientific goals (furthering knowledge, innovation, and other social benefits) and in view of the diversity of possible paths leading to these goals. Consequently, we comprehend peer review as a mechanism of government because its decisions divide the population of the scientific community into governors and governed, thus creating power relations.

From a governmental perspective, these issues of justice are usually discussed in relation to freedom and equality. In this respect, it is worth taking a look at the population of the scientific system in order to conceptualize the relationship of those who govern to those who are governed. First of all, this relationship is characterized by the way it operationalizes the idea of representation. When comparing the scientific community and civic society in this respect, some commonalities and differences are noteworthy: in the scientific community and in civic society those who govern in some way represent those who are governed on principles of impartiality, reflexivity, and proximity. The first notable difference here is that the separation between those who govern and those who are governed is less pronounced in the scientific community. Scientists frequently switch into the roles of being authors, reviewers, or editors. They are not fixed into either being governed or governing. They acquire firsthand experience in how the execution of power works, both from the view of those that govern and those that are governed. In contrast, citizens in civic society are less often actively involved in governing. They mostly see themselves as being governed by professional politicians. And their relations to these politicians are justified as institutionalized forms of representation. First-hand experience in how the execution of power works is relatively rare and is often limited to the act of voting. The division of labor and separation of roles is institutionalized in representative democracy and made permanent by the professionalization of politics.

Moreover, according to Rosanvallon, three principles structure this relation: legibility, responsibility and responsiveness. Legibility refers to the 
reception of information, with interpretative capacities being deployed leading to a comprehensive understanding of and acquaintance with the procedures and mechanisms of governing. These parameters are decisive for understanding how power relations are designed and how power is diffused and executed (Rosanvallon 2018: pp. 202-206). This is very much in line with the manner of representation used by the scientific community in peer review. A democratically literate scientific community means a community that actively comprehends the social world and the mechanisms governing it (Rosanvallon 2018, pp. 214-215). Hence, we consider this the prime principle for analyzing governmentality in science as it allows for accountability and encompasses responsibility. In this sense, legibility characterizes the way in which the two central requirements of quality and legitimacy of judgement are met and specifically how they are mediated via expertise and representation or participation. As processual know-how, legibility is crucial for enabling competent participation. It can convey empowerment and diminishes the distance to power, its mechanisms, and its art of execution. Hence, legibility can be seen as a key element that allows for contribution to, involvement in, and appropriation of governing principles and thus responsive governance in science.

The scientific community consists primarily of professional scientists and science managers. With regard to forms of participation, it is noteworthy that in both the scientific community and civic society membership is conditional: be it in terms of a minimum qualification to participate competently in the expert evaluation procedures or in terms of citizenship and elective franchise. While democratic government obtains its legitimacy through free, equal, and secret elections of representatives, which are mostly professional politicians, and jurisprudence relies on compliance with the law, court procedures, and the impartiality of judges, the scientific community insists on self-government in the form of self-regulation through peer-review procedures, also known as organized skepticism.

Bearing in mind the organizing principles structuring the relation of those who govern and those who are governed worked out by Rosanvallon (legibility, responsibility, and responsiveness), we can now imagine benchmarks that have to be taken into account when designing peer-review procedures with a view to their legitimation as a mechanism of selfgovernment. A legitimate execution of governance in decisions about scarce resources should align its procedures to ensure that it is a) fair in the sense of impartiality, reflexivity, and acceptance of a plurality of paradigms, b) reliably practicable in the sense of functional efficiency, and c) responsible in the sense of accountability because the procedures are legible. In this way, peer review may assert itself as a mediator for moderating external and selfgovernance, thus managing the deep-rooted entanglement of science and politics in a democratically oriented societal environment. 


\section{B I B L I O G R A P H Y}

Abbott, Andrew 2016. Processual Sociology. University of Chicago Press.

Baldwin, Melinda. 2018. "Scientific Autonomy, Public Accountability, and the Rise of 'Peer Review' in the Cold War United States.” Isis 109(3), pp. 538-58.

Barnes, Sherman B. 1934. “The Scientific Journal, 1665-1730.” The Scientific Monthly 38(3), pp. 257-60.

Biagioli, Mario. 2002. "From Book Censorship to Academic Peer Review.” Emergences: Journal for the Study of Media \& Composite Cultures 12(1), pp. 11-45.

Boltanski, Luc/Thévenot, Laurent 2006.: On Justification: Economies of Worth. Princeton: Princeton University Press.

Cole, Jonathan R. and Stephen Cole. 1981. Peer Review in the National Science Foundation: Phase Two of a Study. Washington D.C.: National Academy Press.

Cole, Stephen, Leonard Rubin, and Jonathan R. Cole. 1977. "Peer Review and the Support of Science.” Scientific American 237(4), pp. 34-41.

Foucault, Michel 2006. Sicherheit, Territorium, Bevölkerung. Geschichte der Gouvernementalität I. Frankfurt a. M. Suhrkamp.

Foucault Michel 2005. Dits et Ecrit. Schriften. Vierter Band. Frankfurt a. M.. Suhrkamp.

Guston, David H. 2000. Between Politics and Science: Assuring the Integrity and Productivity of Research. Cambridge University Press.

Guston, David H. 2001. "Boundary Organizations in Environmental Policy and Science: An Introduction.” Science, Technology, \& Human Values 26(4), pp. 399-408.

Hinze, Sibylle 2016.: Forschungsförderung und ihre Finanzierung. In: Simon, D; Knie, A.; Hornbostel, S.; Zimmermann, K. (Hrsg.): Handbuch Wissenschaftspolitik, Springer, pp. 413-428.

Hirschauer, Stefan 2004. Peer Review Verfahren auf dem Prüfstand: Zum Soziologiedefizit der Wissenschaftsevaluation (Peer Review Research Reviews. Sociological Shortcomings of Academic Evaluation). Zeitschrift für Soziologie, 33(1), pp. 62-83.

Hirschauer, Stefan. 2004. "Peer Review Verfahren Auf Dem Prüfstand: Zum Soziologiedefizit Der Wissenschaftsevaluation.” In: Zeitschrift Für Soziologie 33(1), pp. 62-83.

Hirschauer, Stefan 2005. Publizierte Fachurteile. Lektüre und Bewertungspraxis im Peer Review. In: Soziale Systeme 11(1), pp. 52-82.

Hirschauer, Stefan 2010. Editorial Judgements: A Praxeology of "Voting” in Peer Review. In: Social Studies of Science, 40(1), pp. 71-103. 
Hornbostel, Stefan 2016. Forschungsevaluation. In: Simon, D; Knie, A.; Hornbostel, S.; Zimmermann, K. (eds.): Handbuch Wissenschaftspolitik, Springer, pp. 243-260.

Jasanoff, Sheila. 1985. "Peer Review in the Regulatory Process.” In: Science, Technology, \& Human Values 10(3), pp. 20-32.

Jasanoff, Sheila. 1990. The Fifth Branch. Science Advisers as Policymakers. Harvard University Press.

Kleimann, Bernd und Klawitter, Maren. 2017. An Analytical Framework for Evaluation-based Decision-making Procedures in Universities. In: Huisman, J., \& Tight, M. (eds.), Theory and Method in Higher Education, Bingley: Emerald Publishing, pp. 39-57.

Kronick, David. A. 1990. "Peer Review in the 18th-Century Scientific Journal.” JAMA 263(10), pp. 1321-22.

Laine, Christine und Cynthia Mulrow. 2003. "Peer Review: Integral to Science and Indispensable to Annals.” Annals of Internal Medicine 139(12), pp. 1038-40.

Lamont, Michèle. 2009. How professors think: Inside the curious world of academic judgment. Cambridge, Mass: Harvard University Press.

Lamont, Michèle and Guetzkow, Joshua 2016. How Quality is Recognized by Peer Review Panels: The Case of the Humanities. In: Ochsner, Michael; Hug, Sven E.; Daniel, Hans-Dieter (eds.): Research Assessment in the Humanities. Towards Criteria and Procedures, Springer, pp. 31-41.

Lock, Stephen. 1985. A Difficult Balance: Editorial Peer Review in Medicine. Philadelphia: iSi Press.

Luhmann, Niklas 1983. Legitimation durch Verfahren, Frankfurt a. M.: Suhrkamp.

Mallard, Grégoire, Michèle Lamont, and Joshua Guetzkow. 2009. "Fairness as Appropriatenes: Negotiating Epistemological Differences in Peer Review.” In: Science, Technology, \& Human Values 34(5), pp. 573-606.

Merton, R. K. (1938) 'Science and the Social Order', Philosophy of Science, 5(3), p. 321.

Merton, R. K. (1968) 'Science and Democratic Social Structure', in Social Theory and Social Structure. New York/London: Free Press, pp. 604615.

Neidhardt, Friedhelm 2016. Selbststeuerung der Wissenschaft durch PeerReview-Verfahren. In: Simon, D; Knie, A.; Hornbostel, S.; Zimmermann, K. (eds.): Handbuch Wissenschaftspolitik, Springer, pp. 261-277.

Pontille, David und Didier Torny. 2015. "From Manuscript Evaluation to Article Valuation: The Changing Technologies of Journal Peer Review." In: Human Studies 38(1), pp. 57-79. 
Reinhart, Martin. 2012. Soziologie und Epistemologie des Peer Review. Baden-Baden: Nomos.

Reinhart, Martin und Schendzielorz, Cornelia. 2020. Trends in Peer Review. Synthesis Paper for the Social Sciences and Humanities Research Council and the Natural Sciences and Engineering Research Council of Canada.

Rip, Arie. 1985. "Commentary: Peer Review Is Alive and Well in the United States.” In: Science, Technology, \& Human Values 10(3), pp. 82-86.

Rosanvallon, Pierre. 2018. Die gute Regierung. Berlin. Suhrkamp.

Schendzielorz, Cornelia und Reinhart, Martin. 2020. Die Regierung der Wissenschaft im Peer Review. der moderne Staat - Zeitschrift für Public Policy, Recht und Management, 1/2020, 101-123. Opladen: Verlag Barbara Budrich. https://doi.org/10.3224/dms.v13i1.10

Shapin, Steven. 1994. A Social History of Truth: Civility and Science in Seventeenth-Century England. University of Chicago Press.

Spier, Ray. 2002. “The History of the Peer-Review Process.” In: Trends in Biotechnology 20(8), pp. 357-58.

Webster, Charles. 1967. “The Origins of the Royal Society.” In: History of Science 6, pp. 106-28.

Weingart, Peter. 2001. Die Stunde der Wahrheit?: Zum Verhältnis der Wissenschaft zu Politik, Wirtschaft und Medien in der Wissensgesellschaft. Weilerswist: Velbrück Wissenschaft.

Zuckerman, Harriet and Robert K. Merton. 1971. "Patterns of Evaluation in Science: Institutionalisation, Structure and Functions of the Referee System.” Minerva 9(1), pp. 66-100. 